Oprya Ye. V., Melnyk E. V., Pustovoyt M. M., Chernova T. M., Goryachev P. I. Experience of psychiatry distance teaching to english speaking international students. Journal of Education, Health and Sport. 2021;11(08):520-526. eISSN 2391-8306. DOI http://dx.doi.org/10.12775/JEHS.2021.11.08.058

https://apcz.umk.pl/JEHS/article/view/JEHS.2021.11.08.058

https://zenodo.org/record/5584582

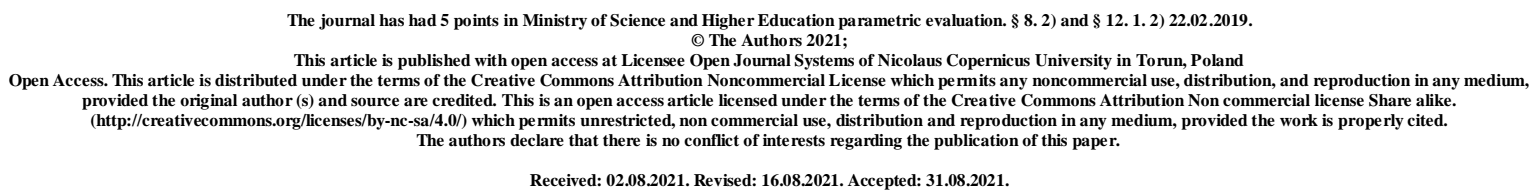

UDK 378.018.43:616.89

\title{
EXPERIENCE OF PSYCHIATRY DISTANCE TEACHING TO ENGLISH SPEAKING INTERNATIONAL STUDENTS
}

\author{
Ye. V. Oprya, E. V. Melnyk, M. M. Pustovoyt, T. M. Chernova, P. I. Goryachev
}

Odessa National Medical University, Odessa, Ukraine

\begin{abstract}
The article describes the difficulties of transition to distance learning (DL) at a medical university when students pass clinical disciplines, using the example of the subject of "psychiatry". The negative impact of the pandemic on international cooperation in the field of education and science was also noted, in particular, attracting foreign students to further education.

Based on the above, the following tasks were set: to study the features of the transition to distance learning the subject of "psychiatry" at the Odessa National Medical University, to identify the features of distance work with English-speaking foreign students during their learning of this discipline and to present proposals for optimizing this process.

During the transition to DL, a significant decrease in the quality of education was noticed during the absence of an existing learning management system, since this transition was a certain stress for all participants in the educational process, both students and teachers. Significant problems have arisen in the DL of clinical disciplines for English-speaking students. The greatest
\end{abstract}


difficulty is the teaching of psychiatry, since it is difficult to explain to students in English not only the description of psychopathological symptoms and syndromes, but also the mental characteristics of people with other nationalities. It is proposed to use movies, with the main heroes suffering from mental disorders, as a thematic guide for mastering practical skills. Although some of the positive aspects of DL have been noted by medical students, they agree to DL only as a forced short-term measure.

Key words: distance learning; psychiatry; English-speaking foreign students; distance educational technologies; international student mobility.

Introduction. Today, there is unlikely to be an area that is not affected by the COVID-19 pandemic. As we all remember, in mid-March 2020, all Ukrainian universities were forced to stop full-time education due to the quarantine restrictions associated with the COVID-19 pandemic, and further establish distance learning (DL) due to the inability to return to standard form of education in a short period of time. The pandemic has put universities in a difficult position, forcing them to adapt to what is happening in the shortest period of time, to spend significant funds on digitalization, and to make decisions often without taking into account the possible consequences. The implementation of DL has become especially problematic for medical universities, take into the account their specific features of education $[1,2]$. Although Odessa National Medical University (ONMedU) eventually switched to the DL mode for all educational programs and in full - in accordance with the previous schedule, but it was especially difficult to do for departments of clinical profile, which requires not only to give the high quality and accessible theoretical knowledge of the discipline to students by physicians, but also to show them patients of the appropriate profile and master the skills of communication with them $[3,4]$.

The pandemic has also had a marked negative impact on international cooperation in the field of education and science, in particular the involvement of foreign students in further education. International students find themselves in a difficult situation as a result of a lack of understanding of the course of events related to the pandemic, and due to the fact that as a result of border closures and flight cancellations many students were unable to return home or return after visiting their country, also some of them faced financial difficulties. This will undoubtedly have a negative impact on the enrollment of foreign students at the university in the future. Many 
analysts expect a significant reduction in the number of current international students and a reduction in the number of enrolled in the next year $[5,6]$.

As we know, education is an important part of young people's lives, but what happens when a student does not receive enough study material in accordance with his requirements due to the fact that he is not allowed to attend the institution to continue his studies for some of the reason [7]. Although the development of relevant computer technologies associated with its implementation gives hope for the improvement of this form of education in the future [8], we will analyze the problems encountered by English-speaking students of the international faculty during distance learning of "Psychiatry" and offer them some possible solutions of it.

\section{The objectives of our work were:}

1. To learn the problems arisen with the implementation of DL.

2. To study the problems faced by English-speaking foreign students at DL.

3. To suggest the solutions of these problems.

\section{Materials and methods of research}

To implement the tasks we used a questionnaire survey of English-speaking students of

the ONMedU international faculty. The survey was completed by 172 students of $4^{\text {th }}$ year of education, who studied in the discipline of "psychiatry" at the Department of Psychiatry, Narcology and Psychology.

\section{Results and discussion}

Universities were forced to solve many acute issues in a short time: in what forms to conduct DL; what technical equipment to use for this purpose; how to evaluate students' assimilation of the received material; how to conduct exams and how to enroll the students for the next academic year. Some students refused from the transition to DL, even require the termination of the contract and a refund for tuition, arguing that DL is not an equivalent replacement for traditional forms of education, as well as due to lack of necessary equipment and poor Internet access.

It should be noted that in beginning of the transition to DL there was a significant reduction in the quality of education regards to the absence of an existing learning management system - software for the administration of university for conduct of DL. There were also problems with online applications through which universities conducted distance lectures or seminars. University websites have been unstable due to the increased load on university 
databases and information systems. The computer literacy of most employees in the transition to online learning was insufficient: there was a lack of knowledge about the available platforms and services for DL, their functionality, effective teaching methods in online format, etc.

From the beginning of implementation of DL teachers of our department used the various forms of the organization of education. Lectures were given in real time online format, were available in the record on the university portal, and ready-made lectures on open resources were used. However, initially the most common forms of replacing the usual lecture format were sending the plan and text of the lecture, presentations and bibliography for independent student work in a group of students created by a laboratory assistant of department on the messenger Viber. But this did not meet the high standards of online learning and online education.

Gradually, teachers switched to real-time lectures and seminars using video conferencing technologies such as Zoom, Webinar and Skype, without reducing the requirements for the amount of study material and knowledge control and providing students with the opportunity to prepare and present to their colleagues that part of the material that interested them. Later, teachers completely understood the need to have in their assets lecture material in audiovisual format, as well as developed content for education, including remote education. The necessity of creation a group of students and responsible teachers in the messenger Viber were also proved in providing quick feedback, especially take into account the time zone difference with students who were unable to return to country of education due to quarantine restriction.

Later, the university administration created its own distance learning system, or as it is called, the learning management system (LMS), based on Microsoft Teams, assigning personal individualized access to the system to each student, teacher and university administration, which was necessary for objective assessment of students, as well as monitoring their attendance at relevant classes.

Despite the widespread belief that DL is rapidly gaining momentum and is gradually displacing the traditional format, or at least competing with it, most students said that until March 2020 they had no personal experience of distance education (77.9\%). That is, in fact, only about a quarter of students had experience of distance learning.

The transition to forced DL was a certain stress for all participants in the educational process. Only one-fifth of students (19.2\%) calmly accepted the need to change the usual form of education. For others, it caused emotions such as depression, confusion, fear and anxiety. Fear 
for their education and passing the final assessment was noted by $24.4 \%$ of students, $30.2 \%$ were confused. At the same time, only $29.0 \%$ of students noted positive emotions from the opportunity to try something new. Among the negative factors of work in the remote format in the first place students put social factors - the lack of student life and personal communication (71.5\%) and lack of direct communication with teachers (55.2\%). These factors are an integral part of DL and require special attention, as personal social interaction is an important and significant part not only of learning but also of everyday life.

Significant problems arise in DL of clinical disciplines for English-speaking students. Teaching psychiatry is the most difficult. It is extremely difficult to convey to students in English both the description of psychopathological symptoms and syndromes and the mental characteristics of people with other nationalities. In order to assess the difference between normal and pathological behavior of the patient, it is necessary to understand the features of the national system of values and beliefs, generally accepted norms of behavior and communication in this area. It is very difficult for students to understand these laws. The situation is complicated by possible technical errors and not always high quality internet connection, which distort the patient's image and often do not allow students to assess non-verbal behaviors that play a significant role in assessing of patient`s psychopathological status.

Therefore, the process of teaching English-speaking psychiatry students requires significant intellectual effort and significant time for teachers to further explanation, which negatively affects the quality of teaching.

Since the survey was conducted after the end of the study cycle, students could also assess their impressions of studying at the department. Half of the students indicated that they had mixed feelings about DL (51.2\%). Every fifth student (19.2\%) called their feelings from distance learning negative. Assessing the effectiveness of their own work on the cycle, a third of students (35.5\%) noted no changes in the transition to DL, $23.8 \%$ of students indicated that the work has become more effective. $38.4 \%$ of respondents record a decrease in the efficiency of their work, and $21.5 \%$ believe that the efficiency "has decreased significantly." At the same time, the vast majority noted that their motivation either did not change $(26.2 \%)$ or even decreased $(51.7 \%)$.

However, despite all the ambiguity of the introduction of DL in the medical university, students noted some of its positive aspects. The main positive features of the students were the 
lack of need to spend time on the road (39.5\%), the opportunity to study in a comfortable home environment $(22.1 \%)$ and the ability to independently distribute their working time $(19.2 \%)$.

Assessing the perspectives of DL, half of students are not even ready to consider transition their education to completely online $-54.1 \%$ and only a small number of students are ready to implement such a transition partly depending on the specifics of the disciplines studied and the epidemiological situation $(36.6 \%)$.

\section{Conclusions}

According to the obtained data, the difficulties faced by students in DL can be divided in two groups: technical problems (Internet speed and quality and lack of the necessary equipment) and personal problems (motivation, self-organization, self-discipline). Difficulties related to psychology have a greater impact, as not everyone can organize themselves, their working hours for regular education. Lack of personal motivation affects the quality of education and can cause its interruption. This should be taken into account when developing and implementing education in a distance format, by organizing interactive classes in which all students will participate. To diversify the methods of presenting information by using graphic, illustrated and video materials, as well as providing students with free access to them, which will increase the availability of information for their perception and help increase the level of interest in the subject.

The use of feature movies with a soundtrack in a language spoken by them, in which the main characters suffering from mental disorders are vividly and in detail presented (for example One Flew Over the Cuckoo's Nest, The Fisher King, A Beautiful Mind, We Need to Talk About Kevin) is especially useful in teaching psychiatry to English-speaking students. Thus, students will not only be interested in further study of the subject, but will be able to practically observe the manner and features of behavior of persons with certain mental disorders.

At DL it is necessary to carry out assessment of all students only on the Microsoft Teams platform, for the purpose of openness, objectification and possibility of control of assessment by university administration. The use of modern methods of communication between teachers and students allows to diversify learning.

Assessing the impact of DL on the development of international student mobility cannot be unambiguous. There is reason to believe that after the end of the coronary crisis, universities will continue to fight for foreign students, but the international educational market will become more sensitive, with more competition. The market may shift to not rich countries, whose 
universities will be able to offer more affordable educational programs. The most important factors in choosing a place of study will be the cost of education, the security of the country and the level of well-being.

\section{References}

1. Materials of the conference "Relevant nutrition for the promotion of the lighting process" - Ivano-Frankivsk, 18 September 2020. - 174p.

2. Kukharenko V.M., Bondarenko V.V. Extreme distance learning in Ukraine: a collective monograph. - Kharkiv, 2020 . - 411 p.

3. Materials of the XVIII All-Ukrainian Scientific and Practical Conference with the international participation "Actual nutrition of medical (pharmaceutical) education: news and perspectives" - Ternopil: "Ukrmedkniga", 20-21 may2021. - 591p.

4. Gomez E., Azadi J., Magid D. Innovation Born in Isolation: Rapid Transformation of an In-Person Medical Student Radiology Elective to a Remote Learning Experience During the COVID-19 Pandemic // Academic radiology. Official journal of the Association of University Radiologists. June 2020. DOI: https: // doi. org / 10.1016 / j.acra.2020.06.001.

5. Surma T., Kirschner P. Technology enhanced distance learning should not forget how learning happens // Computers in Human Behavior. 2020. Vol. 110. September. DOI: https: // doi. org / 10.1016 / j.chb.2020.106390

6. Krishnamurthy S. The future of business education: A commentary in the shadow of the Covid-19 pandemic // Journal of Business Research. 2020. Vol. 117. P. 1-5. DOI: https: // doi.org/10.1016/j.jbusres.2020.05.034 7

7. Qandil A., Abdel-Halim H. Distance e-Learning is Closer than Everybody Thought: A Pharmacy Education Perspective // Health Professions Education. June 2020. DOI: https: // doi. org / 10.1016 / j.hpe.2020.05.004 11 .

8. Govindarajan V., Srivastava A. What the Shift to Virtual Learning Could Mean for the Future of Higher Ed // Harvard Business Review. March 31, 2020. URL: https://hbr.org/2020/03/whatthe-shift-to-virtual-learning-could-mean-forthe-future-of-higher-ed 